\title{
Effects of a low-level diode laser on oral keratinocytes, oral fibroblasts, endothelial cells and osteoblasts incubated with bisphosphonates: An in vitro study
}

\author{
CHRISTIAN WALTER *, ANDREAS MAX PABST ${ }^{*}$ and THOMAS ZIEBART \\ Department of Oral and Maxillofacial Surgery, University Medical Center, Johannes Gutenberg-University Mainz, Germany
}

Received September 4, 2014; Accepted September 30, 2014

DOI: 10.3892/br.2014.389

\begin{abstract}
Bisphosphonate-associated osteonecrosis of the jaw may have multiple causes, including altered bone remodeling, angiogenesis inhibition and impact of bisphosphonate on the soft tissues. Successful treatment is difficult. As a positive effect of low-level laser application on wound healing is well known, an in vitro study was designed to analyze the effect of low-level laser $(280 \mathrm{~mW}, 670 \mathrm{~nm})$ treatment on keratinocytes, fibroblasts, endothelial cells and osteoblasts treated with clodronate, ibandronate, pamidronate or zoledronate. Pure irradiation had a positive effect on cell viability, whereas bisphosphonate treatment had a negative impact. Viability was significantly increased in cells treated with bisphosphonates and sequel irradiation. There was no effect when the bisphosphonate medium was irradiated. The revealed effect of laser stimulation on cell viability is not due to an inactivation of the bisphosphonates. These results may support the idea of low-level laser therapy as a supportive therapy in patients receiving bisphosphonates to prevent and treat bisphosphonate-associated osteonecrosis of the jaw.
\end{abstract}

\section{Introduction}

Bisphosphonates are potent inhibitors of osteoclast activity and are used in patients with bone metastases due to malignant diseases or osteoporosis. Depending on the molecular structure, bisphosphonates can be separated into first, second and third generation bisphosphonates. The first generation bisphosphonates are non-nitrogen-containing, and the second and third generation bisphosphonates are nitrogen-containing

Correspondence to: Dr Christian Walter, Oral and Maxillofacial Surgery, University Medical Center, Johannes Gutenberg-University Mainz, Augustusplatz 2, D-55131 Mainz, Germany

E-mail: christian.walter@unimedizin-mainz.de

*Contributed equally

Key words: bisphosphonates, osteonecrosis, diode laser, cell viability, oral cell lines, bisphosphonate-associated osteonecrosis of the jaw bisphosphonates. The difference between second and third generation bisphosphonates is that the third generation bisphosphonates have substitutes at the nitrogen segment of the molecule.

Through two different mechanisms impacting cell functions, nitrogen-containing and non-nitrogen-containing bisphosphonates cause osteoclast cell death. Whereas non-nitrogen-containing bisphosphonates are built into the phosphate chain of adenosine triphosphate, nitrogen-containing bisphosphonates inhibit farnesyl pyrophosphate synthase (1).

The side-effects of bisphosphonates can be categorized into four major groups: Acute phase reactions, gastro-intestinal side-effects, effects on the kidneys and bisphosphonate-associated osteonecrosis of the jaws (BP-ONJ) (2). These necroses are usually associated with the higher potent nitrogen-bisphosphonates (3).

According to the American Association of Oral and Maxillofacial Surgeons, BP-ONJ is defined as enorally exposed necrotic bone existing for $>8$ weeks, with previous or current bisphosphonate treatment and no radiation of the head and neck area (4).

In the majority of the patients, a further trigger factor in the development of BP-ONJ in addition to the bisphosphonate treatment is often described, such as previous extractions, periodontal diseases, pressure denture sores or surgical procedures $(4,5)$.

Since the etiopathology of BP-ONJ is not definitively known, several theories regarding the development of BP-ONJ are being discussed, which are as follows (6). i) The most common theory describes reduced bone remodeling due to bisphosphonate-induced osteoclast inhibition and accumulation of microfractures (7). ii) Another theory stresses the anti-angiogenic effect of bisphosphonates resulting in the development of avascular osteonecrosis of the jaws. The negative influence of bisphosphonates on endothelial cells is supported by the negative effect on the number of circulating endothelial cells $(8,9)$. iii) Bisphosphonates also have a negative effect on bone covered by soft tissues; this bone is more likely to be exposed $(10,11)$.

All these effects have a negative impact on wound healing and could partially contribute to the development of BP-ONJ. In vitro studies support the negative impact of bisphosphonates on osteoblasts, fibroblasts and endothelial cells $(9,11)$. 
Depending on the prognosis of the underlying disease and the stage of BP-ONJ, several therapy options are carried out. The therapeutic options include mouth rinses, antibiotics, debridements, sequestrectomies, partial resections and continuity resections (4). However, the recurrence rate of BP-ONJ in treated patients is extremely high (4). A previous method used is the ablation of osteonecrotic sites by Er:YAG laser (12). A further supportive option in the treatment of these patients may be the application of low-level laser therapy (LLLT). A positive effect on the proliferation rate of fibroblasts (13) and osteoblasts (14), and the acceleration of bone formation (15) has previously been described.

To evaluate the influence of the effect of LLLT on bisphosphonate-incubated cells involved in wound healing, an in vitro study was performed to investigate the possible positive effect of LLLT on cell viability. The aim of the present study was to investigate the influence of LLLT on cell viability and on the potential to decrease the negative effects of bisphosphonates on cells.

\section{Materials and methods}

Cell culture. Human umbilical cord vein endothelial cells (HUVEC), human gingival fibroblasts (HGF) (Lonza Group AG, Basel, Switzerland), human osteogenic cells (HHOB-c; PromoCell GmbH, Heidelberg, Germany) and human oral keratinocytes (HOK; Provitro, Heidelberg, Germany) were examined. The cells were cultured in an incubator with $5 \% \mathrm{CO}_{2}$ at $37^{\circ} \mathrm{C}$. Cells were passaged at regular intervals depending on their growth characteristics using $0.25 \%$ trypsin (Biochrom $\mathrm{GmbH}$, Berlin, Germany).

HOKs were cultured in keratinocyte growth medium, (Provitro GmbH, Berlin, Germany). The medium contained fibroblast growth factor (FGF), epidermal growth factor (EGF), $\mathrm{Ca}^{2+}<0,1 \mathrm{mmol} / 1$ and insulin, but without bovine pituitary extract and hydrocortisone.

HGFs were grown in stroma cell growth medium (Lonza Group AG) with $1 \%$ penicillin-streptomycin-neomycin antibiotic mixture (PSN), 10\% FCS and $500 \mathrm{ng}$ basic FGF in $500 \mathrm{ml}$ medium.

HUVECs were cultured in an endothelial basal medium supplemented with $1 \mu \mathrm{g} / \mathrm{ml}$ hydrocortisone, $12 \mu \mathrm{g} / \mathrm{ml}$ bovine brain extract, $50 \mu \mathrm{g} / \mathrm{ml}$ gentamicin, $50 \mathrm{ng} / \mathrm{ml}$ amphotericin-B, $10 \mathrm{ng} / \mathrm{mL}$ EGF and $10 \%$ FCS until the third passage.

Osteogenic cells were cultivated in a solution composed of Dulbecco's modified Eagle's medium with $1 \%$ PSN, $1 \%$ L-glutamine and $10 \%$ FCS.

Bisphosphonates. Due to the results of a previous study (16), the cells were incubated with $50 \mu \mathrm{mol}$ of clodronate, ibandronate, pamidronate or zoledronate for $24 \mathrm{~h}$ prior to the cell viability test.

Laser irradiation. The cells were irradiated via a diode laser with $280 \mathrm{~mW}$, at $670 \mathrm{~nm}$ for $60 \mathrm{sec}$ (Periowave; Ondine Biopharma Corp., Toronto, Canada). During irradiation the laser tip was placed in the medium.

Experimental group. The cells were transferred into 24-well dishes for irradiation and bisphosphonate incubation. For each cell line, six different experiments were performed. The first group was the control group with no irradiation or bisphosphonate treatment. The second group underwent irradiation only. The third group had no irradiation but underwent bisphosphonate treatment. The cells in group four were irradiated shortly following incubation with bisphosphonates. The cells in group five were treated vice versa to group four. For the last group, the medium was mixed with bisphosphonates and irradiated prior to placing the osteoblasts into the medium (Fig. 1).

MTT-test. To examine the cell viability of all four cell lines, a 3-(4,5-dimethylthiazol-2-yl)-2,5-diphenyltetrazolium bromide colorimetric assay (MTT M5655; Sigma-Aldrich Produktions $\mathrm{GmbH}$, Steinheim, Germany) was performed. Tetrazolium bromide is fermented to formazan by viable cells. Formazan can be measured photometrically following cell lysis at $550 \mathrm{~nm}$. The experiments were performed six times for each of the groups as specified above.

Statistical analysis. Continuous variables are expressed as mean \pm standard error of mean. Comparisons between groups were analyzed by analysis of variance (ANOVA; post hoc test: Tukey). The software SPSS 16.0 for Windows (SPSS, Inc., Chicago, IL, USA) was used for calculations. $\mathrm{P}<0.05$ was considered to indicate a statistically significant difference.

\section{Results}

ANOVA. For each cell type, the four ANOVAs conducted (one for each bisphosphonate tested) showed significant differences among the control and experimental groups. Each ANOVA yielded a P-value of $<0.001$.

Keratinocytes. The exclusive irradiation of keratinocytes increased cell viability significantly as compared to the control group $(\mathrm{P}=0.015)$. Cells that were only treated with bisphosphonates had reduced cell viability: Clodronate, $\mathrm{P}=0.027$; and ibandronate, pamidronate and zoledronate, $\mathrm{P}<0.001$. There were no significant differences in the two approaches of combining irradiation and bisphosphonate treatment in different orders. The differences between the cells incubated with bisphosphonate and the cells that were additionally irradiated were significant for all the groups $(\mathrm{P}<0.001)$, except for one experimental approach in the clodronate group. In this group, the sequence of irradiation followed by bisphosphonate treatment had no significant difference $(\mathrm{P}=0.285)$, but in the reverse sequence the P-value was 0.010 . For all the other approaches, the $\mathrm{P}$-values were $\leq 0.001$. There was no significant difference between the cells incubated with bisphosphonates and the cells that were grown in bisphosphonate-containing medium that was irradiated (Fig. 1A).

Fibroblasts. Although the viability was increased following laser stimulation, there was no significant difference between the control cells and the cells with laser stimulation in three out of four tests. A significant difference was only obtained in the experiments using ibandronate $(\mathrm{P}<0.001)$. The addition of $50 \mu \mathrm{mol}$ bisphosphonate reduced the viability significantly for ibandronate $(\mathrm{P}=0.001)$, pamidronate $(\mathrm{P}=0.004)$ and zoledronate $(\mathrm{P}<0.001)$, but not for clodronate $(\mathrm{P}=0.336)$. 
A

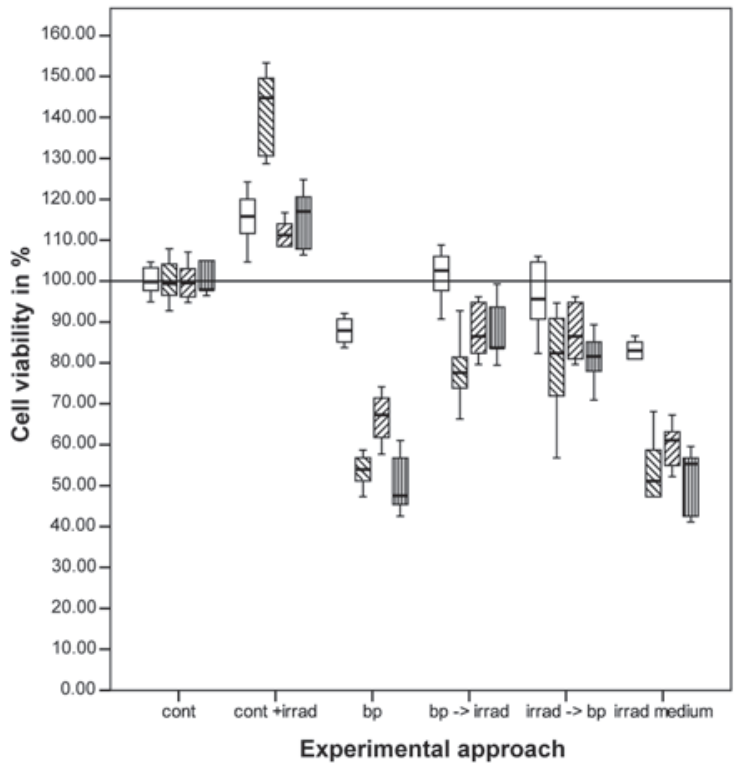

C

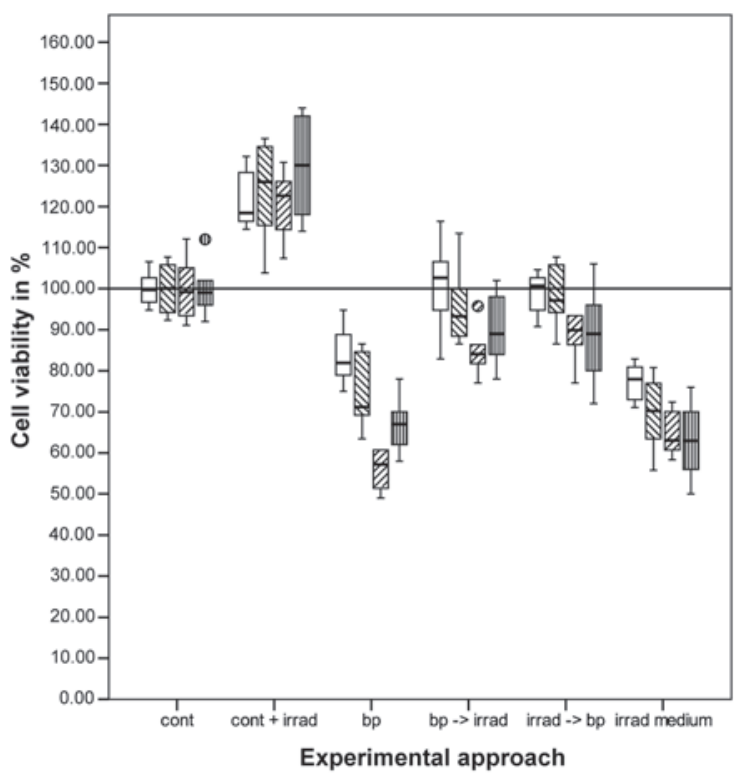

B

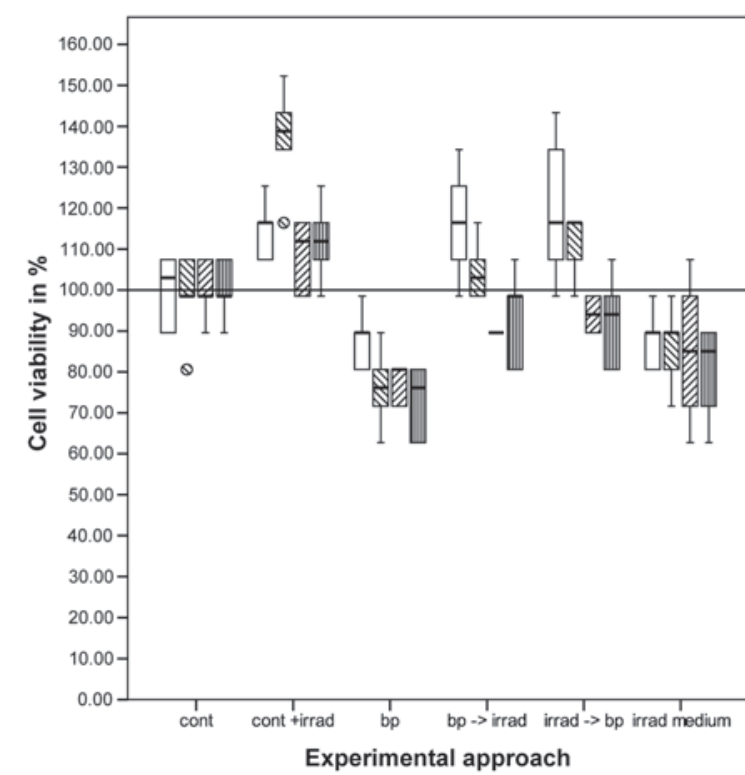

D

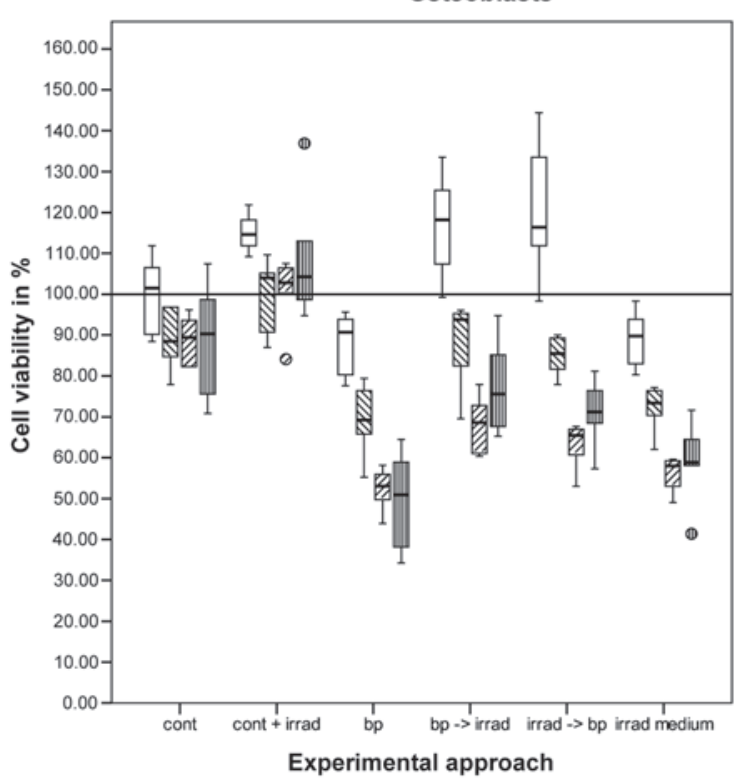

Bisphosphonate

$\square$ Clodronate $\mathbb{N}$ bandronate $\square$ Pamidronate Un Zoledronate

Figure 1. Cell viability test (MTT) for (A) keratinocytes, (B) fibroblasts, (C) human umbilicord vein endothelial cells and (D) osteoblasts treated with bisphosphonates and irradiation. The black bar in the middle of each box represents the median. The box includes all the values between the 25th and 75th percentile. The whiskers indicate the values within the 1.5 interquartile range (IQR). The outliers within 3 IQR are represented as circles. Cont, control; cont + irrad, control + irradiation; bp, bisphosphonates only; bp $\rightarrow$ irrad, bisphosphonate incubation first followed by irradiation; irrad $\rightarrow$ bp, irradiation first followed by bisphosphonate incubation; irrad medium, irradiation of the bisphosphonate medium without cells.

There was no significant difference between the sequence of bisphosphonate treatment and laser treatment, but there was a significant difference between the cells incubated with bisphosphonates only and the cells that were additionally irradiated. P-values for clodronate and ibandronate were $<0.001$, and for pamidronate a P-value of 0.093, compared to the cells incubated with bisphosphonates first and irradiated subsequently. The cells treated with pamidronate in the reverse order (irradiation first) had a P-value of 0.039 . The cells treated with zoledronate had a significance difference with $\mathrm{P}=0.001$ for the two approaches. The analysis of the cells with irradiation of the cell-free bisphosphonate-containing medium revealed no differences compared to the experimental approach with the incubation of cells with bisphosphonates only [P-values ranging between $\mathrm{P}=0.349$ (ibandronate) and $\mathrm{P}=1.000$ (clodronate)] (Fig. 1B).

HUVEC. The treatment consisting exclusively of radiation and bisphosphonates revealed significant changes in cell viability. Irradiation increased the viability, with P-values between $\mathrm{P}<0.001$ and $\mathrm{P}=0.002$, and bisphosphonate treatment decreased the viability, with $\mathrm{P}$-values between $\mathrm{P}<0.001$ and $\mathrm{P}=0.004$. The combination of irradiation and bisphosphonate treatment increased cell viability significantly, independent of order with $\mathrm{P}$-values between $\mathrm{P}<0.001$ and $\mathrm{P}=0.008$. There was no difference between the cells treated with bisphosphonates 
and the cells treated with irradiated medium [P-values between $\mathrm{P}=0.251$ (pamidronate) and $\mathrm{P}=0.981$ (zoledronate)] (Fig. 1C).

Osteoblasts. Low-level laser application increased the viability of cells, but was significant only in the experimental approach with pamidronate $(\mathrm{P}=0.026)$, and had a significant tendency with zoledronate $(\mathrm{P}=0.076)$. Adding bisphosphonates reduced the cell viability in the ibandronate $(\mathrm{P}=0.002)$, pamidronate and zoldedronat-treated assays $(\mathrm{P}<0.001)$. Osteoblasts treated with clodronate had no significant reduction in cell viability. The sequence of irradiation and bisphosphonate treatment did not result in significant differences for any of the cell lines. However, the additional irradiation of the cells treated with bisphosphonates increased the cell viability in all the cases, with $\mathrm{P}$-values ranging from $\mathrm{P}<0.001$ (clodronate) to $\mathrm{P}=0.046$ (pamidronate and zoledronate). There was no significant difference between the cells treated with bisphosphonates only and the cells receiving the bisphosphonate medium that had been irradiated, with $\mathrm{P}$-values ranging between $\mathrm{P}=0.761$ (zoledronate) and $\mathrm{P}=1.000$ (clodronate) (Fig. 1D).

\section{Discussion}

The development of BP-ONJ may be initiated due to several reasons. In addition to the influence of bisphosphonate on several cell lines of the oral cavity (11), further factors are frequently described, including previous tooth extractions, the presence of periodontal disease, pressure denture sores or dental surgical procedures $(3,5)$. Guidelines regarding BP-ONJ have been published worldwide (4,16-18). In addition to treatment recommendations, the prevention of BP-ONJ is emphasized, as successful treatment is difficult due to high recurrence rates.

Frequent recommendations to prevent BP-ONJ include introducing the patient to dental treatment prior to bisphosphonate therapy, with the aim to establish or maintain good oral hygiene. In patients already receiving bisphosphonates, where possible, discontinuing bisphosphonate treatment when a dental surgical procedure is necessary is also being investigated, as well as maintaining good oral hygiene. The CTX-level ( $c$ terminal telopeptide of collagen) as a marker for the risk of developing a BP-ONJ has been discussed previously $(19,20)$. The treatment of BP-ONJ ranges from mouth rinses to resection of the affected area.

The positive effect of low-level laser therapy on cell growth of different cells of the oral cavity is well known (13-15) and used in surgery to accelerate wound repair (21). Explanations for this effect are an increased mitotic activity or changes in collagen synthesis (13). The negative impact of bisphosphonates on different cell lines has been described previously (11). Certain case series have reported the application of laser biostimulation in the treatment of patients with BP-ONJ and reviewed the benefit for patients undergoing this treatment $(22,23)$.

In the present study, the influence of laser stimulation on keratinocytes, fibroblasts, HUVEC and osteoblasts has been analyzed, which are the cells that are negatively influenced by bisphosphonates. The negative impact on all these cells may contribute to the development of BP-ONJ. The results revealed a positive effect of low-level laser stimulation on keratinocytes and endothelial cells, and a negative effect of bisphosphonates on all the tested cell lines. The laser stimulation of bisphosphonate-treated cells increased cell viability in all cell lines, particularly for fibroblasts treated with clodronate, which had even higher levels compared to the control group. The radiation of the bisphosphonate-containing cell medium did not change the cell viability of the different cell lines compared to the experiment approach of cells incubated with bisphosphonate only. An interference of irradiation with bisphosphonate can be excluded, so that the effect is based on the influence of the irradiation on the cells.

In conclusion, these data support the idea of using low-level laser stimulation as a supportive therapy in patients receiving bisphosphonates to avoid BP-ONJ development and in patients being treated due to BP-ONJ.

\section{Acknowledgements}

The authors would like to thank Katherine Joyce (MSE) for the statistical and language assistance. Dr Christian Walter (MD, DDS, PhD) received speaker's fees from Roche (Basel, Switzerland) and financial help for another research project from Novartis.

\section{References}

1. Fleisch H: Bisphosphonates in osteoporosis. Eur Spine J 12: S142-S146, 2003

2. Diel IJ, Bergner R and Grötz KA: Adverse effects of bisphosphonates: current issues. J Support Oncol 5: 475-482, 2007.

3. Walter C, Grötz KA, Kunkel M and Al-Nawas B: Prevalence of bisphosphonate associated osteonecrosis of the jaw within the field of osteonecrosis. Support Care Cancer 15: 197-202, 2007.

4. Ruggiero SL, Dodson TB, Assael LA, Landesberg R, Marx RE and Mehrotra B; American Association of Oral and Maxillofacial Surgeons: American Association of Oral and Maxillofacial Surgeons position paper on bisphosphonate-related osteonecrosis of the jaws-2009 update. J Oral Maxillofac Surg 67: 2-12, 2009.

5. Walter C, Al-Nawas B, Grötz KA, Thomas C, Thüroff JW, Zinser V, Gamm H, Beck J, Wagner W: Prevalence and risk factors of bisphosphonate-associated osteonecrosis of the jaw in prostate cancer patients with advanced disease treated with zoledronate. Eur Urol 54: 1066-1072, 2008.

6. Allen MR and Burr DB: The pathogenesis of bisphosphonate-related osteonecrosis of the jaw: so many hypotheses, so few data. J Oral Maxillofac Surg 67 (Suppl 5): S61-S70, 2009.

7. Mashiba T, Hirano T, Turner CH, Forwood MR, Johnston CC and Burr DB: Suppressed bone turnover by bisphosphonates increases microdamage accumulation and reduces some biomechanical properties in dog rib. J Bone Miner Res 15: 613-620, 2000.

8. Fournier P, Boissier S, Filleur S, Guglielmi J, Cabon F, Colombel $\mathrm{M}$ and Clézardin P: Bisphosphonates inhibit angiogenesis in vitro and testosterone-stimulated vascular regrowth in the ventral prostate in castrated rats. Cancer Res 62: 6538-6544, 2002.

9. Ziebart T, Pabst A, Klein MO, Kämmerer P, Gauss L, Brüllmann D, Al-Nawas B and Walter C: Bisphosphonates: restrictions for vasculogenesis and angiogenesis: inhibition of cell function of endothelial progenitor cells and mature endothelial cells in vitro. Clin Oral Investig 15: 105-111, 2011.

10. Landesberg R, Cozin M, Cremers S, Woo V, Kousteni S, Sinha S, Garrett-Sinha L and Raghavan S: Inhibition of oral mucosal cell wound healing by bisphosphonates. J Oral Maxillofac Surg 66: 839-847, 2008.

11. Walter C, Klein MO, Pabst A, Al-Nawas B, Duschner H and Ziebart T: Influence of bisphosphonates on endothelial cells, fibroblasts, and osteogenic cells. Clin Oral Investig 14: 35-41, 2010.

12. Stübinger S, Dissmann JP, Pinho NC, Saldamli B, Seitz O and Sader R: A preliminary report about treatment of bisphosphonate related osteonecrosis of the jaw with Er:YAG laser ablation. Lasers Surg Med 41: 26-30, 2009. 
13. Pereira AN, Eduardo Cde P, Matson E and Marques MM: Effect of low-power laser irradiation on cell growth and procollagen synthesis of cultured fibroblasts. Lasers Surg Med 31: 263-267, 2002.

14. Fujihara NA, Hiraki KR and Marques MM: Irradiation at $780 \mathrm{~nm}$ increases proliferation rate of osteoblasts independently of dexamethasone presence. Lasers Surg Med 38: 332-336, 2006.

15. Ninomiya T, Miyamoto Y, Ito T, Yamashita A, Wakita M and Nishisaka T: High-intensity pulsed laser irradiation accelerates bone formation in metaphyseal trabecular bone in rat femur. J Bone Miner Metab 21: 67-73, 2003.

16. Khan AA, Sándor GK, Dore E, Morrison AD, Alsahli M, Amin F, Peters E, Hanley DA, Chaudry SR, Dempster DW, Glorieux FH, Neville AJ, Talwar RM, Clokie CM, Al Mardini M, Paul T, Khosla S, Josse RG, Sutherland S, Lam DK, Carmichael RP, Blanas N, Kendler D, Petak S, St-Marie LG, Brown J, Evans AW, Rios L and Compston JE; Canadian Association of Oral and Maxillofacial Surgeons: Canadian consensus practice guidelines for bisphosphonate associated osteonecrosis of the jaw. J Rheumatol 35: 1391-1397, 2008.

17. Grötz KA and Kreusch T: Zahnärztliche Betreuung von Patienten unter/nach Bisphosphonat-Medikation. DZZ 60: 10, 2006 (In German).

18. Bagán J, Blade J, Cozar JM, Constela M, García Sanz R, Gómez Veiga F, Lahuerta JJ, Lluch A, Massuti B, Morote J, San Miguel JF and Solsona E: Recommendations for the prevention, diagnosis, and treatment of osteonecrosis of the jaw (ONJ) in cancer patients treated with bisphosphonates. Med Oral Patol Oral Cir Bucal 12: E336-E340, 2007.
19. Marx RE, Cillo JE Jr. and Ulloa JJ: Oral bisphosphonate-induced osteonecrosis: risk factors, prediction of risk using serum CTX testing, prevention, and treatment. J Oral Maxillofac Surg 65: 2397-2410, 2007.

20. Bagan JV, Jimenez Y, Gomez D, Sirera R, Poveda R and Scully C: Collagen telopeptide (serum CTX) and its relationship with the size and number of lesions in osteonecrosis of the jaws in cancer patients on intravenous bisphosphonates. Oral Oncol 44: 1088-1089, 2008

21. Pinheiro Al, Cavalcanti ET, Pinheiro TI, Alves MJ and Manzi CT: Low-level laser therapy in the management of disorders of the maxillofacial region. J Clin Laser Med Surg 15: 181-183, 1997.

22. Merigo E, Manfredi M, Meleti M, Guidotti R, Ripasarti A, Zanzucchi E, D'Aleo P, Corradi D, Corcione L, Sesenna E, Ferrari S, Poli T, Bonaninil M and Vescovi P: Bone necrosis of the jaws associated with bisphosphonate treatment: a report of twenty-nine cases. Acta Biomed 77: 109-117, 2006.

23. Vescovi P, Merigo E, Manfredi M, Meleti M, Fornaini C, Bonanini M, Rocca JP and Nammour S: Nd:YAG laser biostimulation in the treatment of bisphosphonate-associated osteonecrosis of the jaw: clinical experience in 28 cases. Photomed Laser Surg 26: 37-46, 2008. 